\title{
French translation of the Flow State Scale-2: Factor structure, cross-cultural invariance, and associations with goal attainment
}

(article paru dans : Psychology of sport and exercise, 2007, vol. 8, Nº 6, pp. 897-916-D0I : 10.1016/j.psychsport.2006.07.007)

Jean Fournier ${ }^{a}$, Patrick Gaudreau ${ }^{b}$, Pascale Demontrond-Behr ${ }^{\text {a }}$, Jérome Visioli ${ }^{c}$, Jacques Forest ${ }^{d}$ and Sue Jackson ${ }^{e}$

a Sport Psychology Laboratory, INSEP—National Institute of Sport, 11 Avenue du Tremblay, 75012 Paris, France

${ }^{b}$ School of Psychology, University of Ottawa, 145 Jean-Jacques Lussier, Lamoureux Hall room 352, Ottawa, Ont., Canada K1N 6N5

${ }^{c}$ Activité Physique et Sportive, Université Rennes 2, La Harpe —Avenue Charles Tillon, 35044 Rennes Cédex, France

d Département de Psychologie, Université de Montréal, C.P. 6128 Station Centre-Ville, Montréal, PQ, Canada H3C 3J7

e School of Human Movement Studies, University of Queensland, Level 5 Building 26, St Lucia, Queensland 4072, Australia

\begin{abstract}
Objectives

The goal of this paper was to assess the cross-cultural invariance of the factor structure of the French and English versions of the Flow State Scale-2 (FSS-2) [Jackson, S. A., \& Eklund, R. C. (2002). Assessing flow in physical activity: The Flow State Scale-2 and Dispositional Flow State Scale-2. Journal of Sport and Exercise Psychology, 24, 133-115] and to assess the relationships between athletes' flow state and perceived goal attainment.

Design

Cross-sectional with self-reported questionnaires.

Method

Two samples of sport participants completed the FSS-2 immediately after an event and within a few days after the event, respectively. Data were analyzed with reliability and confirmatory factor analyses as well as with correlational and regression analyses.

Results

Results of confirmatory factor analyses on the French FSS-2 replicated the factor structure of the original FSS-2 with the first-order 9-factor and the hierarchical models both displaying adequate level of goodness-of-fit. Results of multi-sample analyses indicated that most parameters of the FSS-2 were invariant across languages. As expected, flow state correlated significantly with goal attainment during a sport competition. The relationship between flow and goal attainment was invariant across levels of competition.

Conclusions

This study provided support for the factor structure of the French version of the FSS-2 and for the invariance of the flow construct across languages. Flow state is significantly associated with goal attainment and the relationship is equivalent across athletes' levels of competition.

Keywords: Flow state; Positive psychology; Cross-cultural validity; Factor analysis; Goal attainment; Performance; Sport
\end{abstract}




\section{Introduction}

Emotional states have received considerable empirical and theoretical attention in sport and exercise psychology (Crocker \& Graham, 1995; Hanin, 2000; Jackson, 2000). Researchers have focused predominantly on negative psychological states such as anxiety (Burton, 1998; Kleine, 1990), anger (Beedie, Terry, \& Lane, 2000; Isberg, 2000), and stress (Gould, Jackson, \& Finch, 1993; Madden et al., 1995). Based on the premise that participation in sport is inherently pleasurable, a line of inquiry has emerged to provide empirical attention to positive psychological states such as enjoyment (Carpenter, Scanlan, Simons, \& Lobel, 1993), optimal experience (Cohn, 1991), satisfaction (Riemer \& Chelladurai, 1998), and flow (Jackson, 2000). This study, embedded in this latter line of research, presents the cross-cultural validation of an instrument designed for the assessment of flow state in sport and physical activity.

\section{Dimensions of flow}

Mihaly Csikszentmihalyi has examined flow state in a variety of life-domains such as work, school, art, leisure, and sport (Csikszentmihalyi \& Csikszentmihalyi, 1988). Based on these studies, flow has been described as a psychological state in which the challenges of a situation and one's personal skills are at an equally high level. When experiencing flow, people are in a state of grace characterized by an effortless and pleasurable feeling of engagement with the task at hand. They feel so deeply involved that they experience a feeling of unity with the activity as well as a sensation of total control. As a consequence, they often perform to the best of their capacity with a sense of automaticity and a high level of confidence.

Csikszentmihalyi (1990) has presented nine characteristics, each representing a distinctive conceptual dimension of the flow experience. These nine dimensions represent, as a whole, the flow experience (Jackson \& Eklund, 2002). Qualitative studies have indicated that athletes experience these nine characteristics during flow (Jackson (1992) and Jackson (1995); Jackson \& Roberts, 1992).

In flow, athletes perceive the situation as challenging, while believing that their skills will enable them to cope effectively with the demands of the situation. This sense of congruence between situational demands and personal resources represents the challenge-skill balance dimension of flow. Flow also includes a feeling of effortless engagement in which the person is deeply absorbed by the task at hand. This merging of action and awareness often produces a sensation of automaticity and unity with the activity. As such, athletes in flow are able to sustain their concentration effortlessly (i.e., total concentration) and they stop worrying about the self and about how other people might evaluate them (i.e., loss of self-consciousness). They can also lose their habitual sense of passage of time (i.e., time transformation). Some athletes in flow might perceive that the situation unfolds in slow motion whereas others may perceive that time is speeding up. Flow experience also includes a dimension of intrinsically pleasurable engagement. This autotelic experience of intense enjoyment arises because athletes in flow are performing the activity for its own sake. A sence of total control, in which people perceive that they are exercising control over an activity, is another characteristic of flow state. When experiencing flow, people have clear goal and a strong "feeling of certainty about what one is going to do" (Marsh \& Jackson, 1999). They also perceive unambiguous feedback, provided inherently by the situation, which informs them accurately about the outcome of their actions. In return, this feedback provides athletes with a clear plan of actions enabling them to enhance performance in their activity.

\section{Flow state scale (FSS)}

Jackson and Marsh (1996) developed a self-reported questionnaire for the assessment of flow in sport and exercise. Items of the questionnaire were developed by drawing on other self-reported scales of flow and raw data themes reported in qualitative studies conducted with elite athletes (Jackson (1992) and Jackson (1995)). The initial version of the FSS, which contained nine six-item subscales, was completed by 394 American and Australian athletes. Each subscale measured one of the nine distinct dimensions of flow. Based on the results of reliability and confirmatory factor analyses (CFA) on 381 athletes, four items were selected for each subscale (Jackson \& Marsh, 1996). The internal consistency of the scales ranged from 0.80 to 0.86 , with a mean reliability of 0.83 . Results of a CFA have provided evidence for the tenability of the hypothesized first-order factor model. Interestingly, the inter-scale correlations were all significant and their moderate size lent support for the conceptual 
distinctiveness of the nine dimensions of flow and for their interconnectedness during flow experiences. These results were replicated with an independent sample of 385 athletes at the 1994 World Master Games (Marsh \& Jackson, 1999).

Based on the hierarchical nature of flow proposed by Csikszentmihalyi (1990), Jackson and Marsh (1996) have suggested that the correlations between the nine dimensions of flow might be explained by a second-order global factor. Results of hierarchical confirmatory factor analyses (HCFA) have provided equivocal support for this contention (Jackson \& Marsh, 1996; Marsh \& Jackson, 1999). On the one hand, the relative fit indices (e.g., CFI, NNFI, RMSEA) have reached their respective cut-off value. On the other hand, the likelihood ratio test (i.e., difference in $x^{2}$ value across nested models) revealed that the second-order model provided a significantly worse fit than a model with nine firstorder factors. More importantly, a substantial percent of the variance of time transformation and loss of self-consciousness was not explained by the global factor of flow (Jackson \& Marsh, 1996). In the study of Marsh and Jackson (1999), the second-order loading of time transformation was nonsignificant. In sum, the hierarchical model provides an acceptable fit to the data but it nonetheless possesses some important conceptual limitations (Tomarken \& Waller, 2003).

In an attempt to replicate these results, Vlachopoulos, Karageorghis, and Terry (2000) have submitted the FSS to a sample of 1231 aerobic classes participants from England. Results of CFA and HCFA have respectively shown the acceptable fit of a nine first-order factor model and the lack of fit of the hierarchical model. Despite this encouraging finding, the relative fit indices were lower than those reported in previous studies (Jackson \& Marsh, 1996; Marsh \& Jackson, 1999), the internal consistency of time transformation was somewhat problematic $(\alpha<0.70)$, and the standardized loadings of two items of that scale were relatively small $(\lambda<0.50)$. Of particular interest was the high standardized covariance $(\varphi>$.80) between four pairs of first-order factors: (1) challenge-skill balance and feedback, (2) challenge-skill balance and sense of control, (3) clear goals and feedback, (4) clear goals and sense of control. To some extent, this finding calls into question the discriminant validity of some of the items representing these sets of factors in this sample.

\section{Flow State Scale-2 (FSS-2)}

Jackson and Eklund (2002) revised the FSS by developing alternative items to replace some of the original items of the FSS, particularly from the time transformation and loss of self-consciousness subscales. Thirteen new items were incorporated into a 49-item questionnaire. Based on the results of an iterative CFA, five items were replaced to enhance the conceptual coherence of the existing subscales. The resulting questionnaire, labelled the FSS-2, was cross-validated on an independent sample of 422 sport participants. Results of CFAs and HCFAs provided evidence for the factorial validity of the hypothesized first-order factor model as well as for the hierarchical model. Although the FSS-2 shares some of the limitations of its predecessor (i.e., low second-order loading for time transformation and loss of self-consciousness), it should nonetheless be considered as a useful and valid instrument for the measurement of the nine underlying dimensions of flow state.

\section{Correlates of flow state}

Despite some limitations with the hierarchical model, the FSSs (i.e., initial and modified versions) are undeniably useful for research in sport settings. Using structural equation modeling with latent variables (SEM), Marsh and Jackson (1999) have shown associations between the dimensions of flow and variables such as perceived sport ability, perceived skill, and self-reported concentration. Karageorghis, Vlachopoulos, and Terry (2000) have also shown a significant association between the global flow factor (i.e., second-order latent score) and post-exercise positive engagement, revitalization, and tranquillity states. Other studies have indicated that the dimensions of flow were significantly associated with perceived ability, anxiety (Jackson, Kimiecik, Ford, \& Marsh, 1998), selfdetermination (Jackson et al., 1998; Kowal \& Fortier, 2000), areas of self-concept, and basic psychological skills (Jackson, Thomas, Marsh, \& Smethurst, 2001).

Flow state has been conceived as an optimal experience related to optimal functioning, higher wellbeing, and exceptional performances. Sparse empirical attention has been devoted to the flowperformance relation. Yet, the literature suggests a moderate relationship between flow and absolute indices of performance. In a study by Jackson and her collaborators (Jackson et al., 2001), several 
dimensions of flow related significantly to subjective and normative performance ratings. Nonetheless, a major part of inter-individual differences in sport performance is determined by physical, biomechanical, technical, and tactical factors that cannot be overcome by psychological processes such as flow state. Goal attainment, however, is predominantly determined by self-regulatory processes and may contribute to a better understanding of optimal psychological experience. As a consequence, individual differences in flow state during a competition might relate substantially to the extent to which athletes attain their goals or fail to perform to the best of their capacities at a given moment in time. Clearly, correlational designs are inadequate to determine whether goal attainment should be conceived as an outcome or as a mere concomitant of flow state. Nonetheless, examining the correlation between flow state and goal attainment is required to provide evidence for the concurrent validity of the flow construct, as assessed by the FSS-2. Marsh and Jackson (1999) have reported significant correlations between dimensions of flow and proxy measures of goal attainment (i.e., perceived success and satisfaction with sport). People can use absolute, self-referenced, and normative criteria to assess the extent to which they feel successful at attaining their goals (Elliot \& Dweck, 2005). Research has yet to examine flow state within a well-articulated multidimensional framework of goal attainment. In this study, it was assumed that higher flow state would correlate with higher levels of attainment of mastery, self-referenced, and normative goals.

\section{The present study}

Most sport psychology research on flow state has been conducted with English-speaking participants. In a qualitative study of French-Canadian snowboarders, only eight dimensions of flow were identified as time transformation failed to emerge as an important characteristic of flow state (Forest, 2001). Although this finding mirrors the equivocal status of time transformation in the FSSs, cross-cultural research is needed to examine flow with French-speaking athletic populations from Europe and North America. Cross-cultural validation is an important step to ensure the equivalence of measurement instruments across languages and cultures, thus providing a direct test for their external validity. Replicating the factor structure of the FSS-2 across different countries is needed to ensure that the operationalization of the flow state construct is not biased by colloquialisms and by idiosyncrasies of the particular language in which it was originally developed.

This article presents a study on the cross-cultural translation and validation of a French version of the FSS-2. The aim of this study was fivefold. A first goal was to assess the internal consistency of the nine subscales of the French FSS-2 and to compare it with data from prior validation studies on the original FSS-2 (Jackson \& Eklund, 2002). On the basis of CFA, a second goal was to provide empirical evidence for the tenability of the hypothesized 36-item 9-factor model of the FSS-2 with a sample of French-speaking athletes from France and Canada. Within the confines of HCFA, a third goal was to study the tenability of a hierarchical model in which the nine first-order factors load on a second-order factor representing global flow state. Although this model was expected to be substantially inferior to the first-order model on purely statistical grounds, it was nonetheless hypothesized to provide reasonable fit to the data. A fourth goal was to examine the cross-cultural measurement invariance of the FSS-2 across samples of French- and English-speaking participants. Using the data originating from the validation study by Jackson and Eklund (2002), a series of increasingly stringent invariance tests (i.e., first-order loadings, second-order loadings, uniquenesses, and disturbances) were performed to evaluate the cross-cultural equivalence of the parameters from the hierarchical model of the FSS-2. A final goal was to provide evidence of concurrent validity of the French FSS-2 by examining the relationship between flow state and perceived goal attainment in a competitive sport encounter. Based on a multidimensional conception of goal attainment, the second-order flow factor was expected to correlate positively with self-reported indices of mastery, self-referenced, and normative goal attainment.

\section{Method}

\section{Cross-cultural translation of the FSS-2}

The preliminary version of the French FSS-2 was created using a back translation procedure. A bilingual sport scientist translated the FSS-2 into French and a second bilingual person retranslated it into English. The French items were translated in a way that maximized their linguistic and conceptual correspondence with their original counterparts. A research committee, that included the authors of 
this article, compared the wording of the French and English forms of the questionnaire and created an initial version of the French FSS-2 on the basis of consensual agreement.

A pilot study was performed with a sample of 287 athletes from France. The coefficients of internal consistency ranged from 0.61 to 0.93 , with a mean of 0.78 . Compared with the original FSS-2, the coefficients of internal consistency were substantially weaker (Jackson \& Eklund, 2002). Results of CFA also failed to support the hypothesized 9-factor model ${ }^{1}$. Even after the deletion of five problematic items, the model did not yield an acceptable fit to the data ${ }^{2}$. Of particular concerns, modification indices indicated that several items could cross-load on non-hypothesized factors. These results, which highlighted the psychometric problems of the French FSS-2, were taken to suggest that several items were unreliable indicators of the flow dimension they were trying to measure.

In an attempt to address these problems, three to five alternative formulations were created for each of the 36 items of the French FSS-2. Eight sport scientists from France and Canada provided feedback about cross-cultural equivalence, linguistic style, clarity, and content relevance of each item. These bilingual researchers were familiar with flow literature in sport psychology and cross-cultural translation methods. A research committee, that included the authors of this article, reviewed the feedback provided by researchers and prepared a substantial revision of the French FSS-2. An effort was made to ensure that the translated items were short, unambiguous, conceptually relevant, and linguistically equivalent to their original English counterparts. Eleven items remained unchanged and 14 items were slightly modified, whereas 11 items were substantially reworded. A decision was also taken to use language that would make the items understandable to teenagers and to use International French to avoid colloquialism that could render the instrument inapplicable in specific French-speaking subpopulations.

\section{Participants}

\section{French-speaking sample}

Four hundred and twenty-five French-speaking athletes (51\% from France and 49\% from Quebec) participated in this study. These athletes (53\% male) were ranging from 12 to 68 years of age $(M=21.83, S D=7.94)^{3}$ and they have been competing in their sport for an average of 10 years $(S D=6.97)$. They were recruited from various individual and team sports and they participated in leisure/recreational (16\%), departmental/regional $(28 \%)$, regional/provincial $(29 \%)$, national $(21 \%)$, and international $(6 \%)$ sport events.

\section{English-speaking sample}

Data from the cross-validation sample by Jackson and Eklund (2002) were used for the cross-cultural invariance analyses. Four hundred and twenty-two English-speaking athletes/exercisers participated in this study. These participants ( $48 \%$ male) were ranging from 16 to 82 years of age $(M=26.3, S D=11.1)$ and they were participating in a wide variety of activities ranging from football to exercise activities such as aerobics. They were participating in a large variety of club/school $(23 \%)$, state $(17 \%)$, collegiate $(16 \%)$, national $(11 \%)$, international $(5 \%)$, and other sport/exercise activities. More information about this sample can be found in Jackson and Eklund (2002).

\section{Measures and procedure}

\section{Flow state}

French-speaking participants have completed the French FSS-2 whereas English-speaking participants have completed the FSS-2 (Jackson \& Eklund, 2002). Although standardized instructions were given to all participants, the design of the research differed across samples. On the one hand, English-speaking participants completed the FSS-2 immediately upon the conclusion of their sport activity. On the other hand, French-speaking participants completed the French FSS-2 in relation to their latest sport competition. The reference to a sport competition seemed more appropriate to examine the relationship between flow and goal attainment. Furthermore, a retrospective design, which is common in sport psychology research, might allow generalization of the FSS-2 factor structure in settings where athletes are unavailable within hours after a competition. Using a 5-point 
Likert-type scale ranging from 1 (strongly disagree) to 5 (strongly agree), athletes were asked to indicate the extent of their agreement with each of the items as characterizing their experience in the event just completed (English sample) or in their latest competition (French sample).

\section{Perceived goal attainment}

French-speaking participants have completed the attainment of sport achievement goal scale (ASAGS, Gaudreau, Amiot, Blondin, \& Blanchard, 2002) to assess goal attainment. Using a 7-point Likert-type scale ranging from 1 (does not correspond at all) to 7 (corresponds completely), athletes were asked to indicate the extent to which each item corresponded to their performance during the competition. The A-SAGS contains three four-item subscales measuring different, yet interrelated, criteria of goal attainment: Mastery (e.g., "I mastered the difficulties of the situation"), self-referenced (e.g., "I did better than my usual performances"), and normative (e.g., "I outperformed other athletes"). Results of CFA lent credence to the factor validity of this three-factor model (Gaudreau et al., 2002). Correlations with objective criteria of performance-goal discrepancy have provided support for the concurrent validity of this instrument (Gaudreau \& Blondin, 2004).

\section{Overview of analyses}

Descriptive statistics were examined in order to identify problematic items (i.e., low standard deviations, skewness $> \pm 3$, kurtosis $> \pm 7$, West, Finch, \& Curran, 1995). The coefficients of internal consistency were calculated and compared with the original values of the FSS-2 (Jackson \& Eklund, 2002). A series of maximum likelihood CFA and HCFA were performed using the covariance matrix from EQS 5.7 software (Bentler, 1995). Two models were tested to assess the tenability of both a 36item 9-factor model and a hierarchical model with the nine first-order factors loading on the secondorder flow factor. Along with the $x^{2}$ statistic, the following goodness-of-fit indices were used in model evaluation: comparative fit index (CFI), non-normed fit index (NNFI), and root mean square error of approximation (RMSEA). Values between 0.90 and 0.94 for the CFI and NNFI indicate acceptable fit, whereas values of 0.95 and higher indicate relatively good fit. Values smaller than 0.08 for the RMSEA indicate acceptable fit, whereas values smaller than 0.05 indicate close fit. RMSEA $90 \% \mathrm{Cl}$ was also used to assess hypotheses of close fit (RMSEA $<0.05)$ and not-close fit $(R M S E A>0.08)$. When the upper bound of the RMSEA $90 \% \mathrm{Cl}$ was below 0.05 , the not-close fit hypothesis was rejected and the close fit of the model was assumed. In contrast, when the RMSEA $90 \% \mathrm{Cl}$ straddled 0.05 , the notclose fit hypothesis was not ruled out and the close fit of the model could not be assumed (MacCallum, Browne, \& Sugawara, 1996). Goodness-of-fit indices were compared with prior validation studies on the FSS-2 to interpret the factor validity of the translated French version.

A final set of analyses was performed to assess the cross-cultural invariance of the FSS-2 across French and English languages. Within the confines of multiple-sample HCFA, four hierarchically nested models were tested to assess the configural, as well as the invariance of first-order factor loadings, second-order factors loadings, and error variances (i.e., uniqueness and disturbance). As recommended by Vandenberg and Lance (2000), $\Delta x^{2}$ and $\Delta C F I$ values were both used to assess factorial invariance. Either a $\Delta$ CFI of at least -0.002 or a significant $\Delta x^{2}(p<0.05)$ had to be observed to reject the null hypothesis of invariance. Although more conservative that the suggested cutoff of $\Delta \mathrm{CFI}-0.01$ (Cheung \& Rensvold, 2002), the current decisional rule was deemed more appropriate given the numerous parameters constrained to equality in the hierarchical model. Given evidence of non-invariance, the specific non-invariant parameters were identified using univariate Lagrange multiplier $x^{2}\left(L M x^{2}\right)$. Equality constraints were released only if their corresponding $L M x^{2}$ were significant at $p<0.01$, to avoid capitalizing on chance (Green, Thompson, \& Babyak, 1998). A main goal was to assess if the loadings of the nine flow dimensions on the second-order flow factor could be assumed invariant across French and English versions of the FSS-2. A prerequisite was to demonstrate that a majority of first-order factor loadings of each factor were invariant across languages. Establishing the full or at least the partial first-order metric invariance was deemed to be a sufficient condition to ensure the reliable cross-cultural comparison of the second-order factor loadings (Byrne, Shavelson, \& Muthén, 1989; Steenkamp \& Baumgartner, 1998).

\section{Results}


Three participants failed to complete more than five items of the French FSS-2 and were excluded from further analyses. Six participants failed to complete one or two items and these missing data were imputed with sample mean. Using the critical value of the Mahalanobis distance, $x^{2}{ }_{(36)}=67.99$, $p<0.001,35$ multivariate outliers were identified. These participants departed severely from the remainder of the sample $(Z>|3.00|)$ on several items. These 35 cases were excluded and further analyses were performed on a sample of 387 athletes.

\section{Descriptive statistics and internal consistency}

French-speaking participants have used the whole rating scale, with their responses ranging from 1 to 5 on each of the 36 items. The mean (average $=3.74$, from 3.27 to 4.17), standard deviations (average $=0.95$, from 0.74 to 1.19 ), skewness (average $=-0.49$, from -1.25 to -0.10 ), and kurtosis (average $=-0.19$, from -0.81 to 1.19 ) of the items indicated small departures from univariate normal distribution. The Mardia's coefficient of multivariate kurtosis was 156.01 (normalized=29.33), thus suggesting that a multivariate normal distribution could not be assumed in this sample. Nonetheless, the multivariate kurtosis was consistent with prior research on the FSS (e.g., Vlachopoulos et al., 2000) and the departure from multivariate normality was small enough to be addressed using the Satorra-Bentler rescaled $X^{2}\left(\mathrm{SBX}^{2}\right)$, the Robust $\mathrm{CFI}(\mathrm{RCFI})$, and the Robust standard errors of parameter estimates in the CFA and HCFA.

The alpha coefficients indicated that the reliability of each of the nine subscales was adequate to quite good, with internal consistency ranging from 0.79 to 0.92 (see Table 1). These results, which were consistent with the validation study of Jackson and Eklund (2002), provided evidence for the adequate internal consistency of the nine subscales of the French FSS-2.

\section{Confirmatory factor analysis}

The hypothesized 36-item 9-factor model was tested using an oblique CFA. All goodness-of-fit indices reached acceptable values, with RMSEA suggesting close fit of the model (see Table 2). The hypothesis of not-close fit could not be ruled out as the upper bound of RMSEA $90 \%$ Cl was slightly above 0.05 . However, the fit of the model was at least as good, if not slightly superior, to the results obtained with the original version of the FSS-2 (i.e., RMSEA $90 \% \mathrm{Cl}=0.055$ ). The standardized factor loadings were, on the whole, substantial, ranging from 0.42 to $0.94(\mathrm{M}=0.78, \mathrm{SD}=0.12$; see Table 3$)$. The inter-scale correlations ranged from 0.05 to $0.76(\mathrm{M}=0.40, \mathrm{SD}=0.20$; see Table 4$)$, thus suggesting that the nine factors are tapping unique, yet correlated, dimensions of flow state. These results, which were highly comparable with data by Jackson and Eklund (2002), were taken to suggest that the French FSS-2 provided a reasonable, if not close fit to the data.

On the basis of the inter-scale correlations, two alternative 8-factor models were compared to the 9factor model. A first model, in which the items from unambiguous feedback and sense of control loaded on a single factor, provided poorer fit to the data than the 9-factor model, $\Delta \mathrm{x}^{2}=112.48, \Delta \mathrm{df}=8$, $p<0.001, \Delta C F I=-0.020$. Similar results were obtained for a second model in which the items from sense of control and challenge-skill balance loaded on a single factor, $\Delta x^{2}=213.49, \Delta d f=8, p<0.001$, $\Delta \mathrm{CFI}=-0.023$. Overall, these results provided evidence for the relative superiority of a model with nine first-order factors.

\section{Hierarchical confirmatory factor analyses}

The 36-item hierarchical model with the nine first-order factors loading on a second-order factor of flow was tested using HCFA. As expected from prior studies on the FSSs, the hierarchical model yielded a significantly worse fit to the data than the first-order model, $\Delta x^{2}=98.30, \Delta d f=27, p<0.001$. Although relatively inferior on purely statistical grounds, goodness-of-fit indices of the hierarchical model have nonetheless reached acceptable values, with RMSEA suggesting close fit of the model (see Table 2). As per the first-order model, the hypothesis of not-close fit could not be ruled out, with an upper bound of RMSEA $90 \% \mathrm{Cl}$ above 0.050 . However, the fit of the model was at least as good, if not slightly superior to the results obtained with the original version of the FSS-2 (i.e., RMSEA $90 \% \mathrm{Cl}=0.058$ ). The magnitude of eight standardized second-order factor loadings was substantial, ranging from 0.46 to $0.90(\mathrm{M}=0.63, \mathrm{SD}=0.23)$. As with prior studies on the hierarchical structure of the FSSs, time transformation failed to load substantially on the flow second-order factor (Jackson \& Eklund, 2002; 
Jackson \& Marsh, 1996; Marsh \& Jackson, 1999; Vlachopoulos et al., 2000). This result supports previous suggestions that time transformation may not be a salient dimension to some athletes' flow experience. These results, which are highly comparable with data by Jackson and Eklund (2002), were nevertheless taken to suggest the reasonable fit of the hierarchical model of the French FSS-2. Given the superior fit of the first-order model and the greater parsimony of the hierarchical model, both were deemed to provide a complementary portrait of flow state of athletes.

\section{Multiple-group hierarchical confirmatory factor analyses ${ }^{4}$}

The 36-item hierarchical model of the FSS-2 was tested for invariance across languages. Results of the configural invariance model suggested that the number of latent constructs as well as the pattern of fixed and freed factor loadings could be assumed invariant across languages. Comparison of the first-order metric invariance model with the configural model indicated that 25 out of the 27 freed firstorder loadings could be assumed invariant. Significant modification indices showed that item 18 $\left(L M X^{2}=18.07 ; \lambda_{\text {French }}=0.87, \lambda_{\text {English }}=0.77\right)$ and item $25\left(L M X^{2}=10.03 ; \lambda_{\text {French }}=0.68, \lambda_{\text {English }}=0.78\right)$ could not be assumed invariant across samples. Nonetheless, the size of these factors loadings was substantial in both languages, thus implying that the items were reliable indicator of their factors in both versions of the FSS-2. Given that only one item per factor was non-invariant, partial first-order metric invariance was tenable for autotelic experience and loss of self-consciousness whereas the full invariance was assumed for the other seven dimensions of flow.

Results of the second-order metric invariance model revealed that eight out of the nine second-order loadings could be assumed invariant. ${ }^{5}$ The loading of autotelic experience on the second-order flow factor was significantly different across samples $\left(L M X^{2}=9.76 ; \lambda_{\text {French }}=0.48, \lambda_{\text {English }}=0.65\right)$. This finding will be explained more extensively in the discussion. Finally, the error variances invariance model suggested that 16 uniquenesses and 2 disturbances were significantly different across languages. This result is mostly inconsequential as the invariance of error variances is a stringent condition to strive for, but rarely attained in analyzing item-level cross-cultural data (Steenkamp \& Baumgartner, 1998).

Relationships between flow and goal attainment

Bivariate correlations were used to assess the relationships between flow state and goal attainment (see Table 5). Given the number of correlations tested and the large sample size, a stringent alpha level of $p<0.01$ was used. At a second-order level, a global dimension of flow correlated significantly with global goal attainment and with each subtypes of goal attainment (i.e., mastery, self-referenced, and normative). At a first-order level, all dimensions of flow-with the exception of time transformation and loss of self-consciousness-correlated significantly with goal attainment indices. These results will be addressed more extensively in the discussion.

Finally, a moderated hierarchical regression analysis was performed to assess whether the relationship between global flow and global goal attainment differs according to athletes' level of expertise (1=recreational, 2=regional, 3=provincial, 4=national, 5=international). At the first step, expertise level was entered along with the centered score of flow state. At the second step, the multiplicative term of expertise level and centered flow state was entered (Aguinis, 2004; Cohen, Cohen, West, \& Aiken, 2003). Results indicated that the interaction between expertise level and flow state was not significant, $\Delta F(1,382)=2.59, p>0.10, \Delta R^{2}=0.003, \beta=0.15, p>0.10$. At the first step, both flow state, $\beta=0.61, p<0.01$, and expertise level, $\beta=0.10, p=0.01$, were significantly associated with goal attainment, $F(2,383)=134.14, p<0.01, \Delta R^{2}=0.412$. Hence, these results suggest that the relationship between flow state and goal attainment is invariant across expertise levels, thus providing additional evidence for the concurrent validity of the French FSS- $2 .{ }^{6}$

\section{Discussion}

Factor structure of the French FSS-2

This study extends the examination of the FSS-2 factor structure with a sample of French-speaking participants from France and Canada. Results provided evidence for adequate to good internal consistency of the nine subscales, as well as for the suitability of the hypothesized first-order and 
hierarchical models of the French FSS-2. Of particular interest, the fit of both models was at least as good, if not slightly superior, to the results obtained with the original version of the FSS-2. All firstorder factor loadings were significant and reasonably substantial. Consistent with prior literature, one could conclude that the 9-factor first-order model is superior to the hierarchical model in which the nine dimensions of flow are loading on a second-order flow factor. In the meantime, the hierarchical model should be considered more parsimonious as it summarizes 36 inter-factor correlations with only nine second-order loadings. Given the superior fit of the first-order model and the greater parsimony of the hierarchical model, both were deemed to provide a complementary portrait of flow state of athletes. On the one hand, a first-order model might be useful for a detailed examination of the antecedents and consequences of flow. Hence, it might facilitate the identification of specific flow dimensions most strongly associated with important correlates of flow state. On the other hand, relying on a global flow dimension might contribute to more accurate estimation of parameters in regression analyses given the moderate to high level of interdependence between the nine subscales of the FSS-2. Despite the relative utility of the hierarchical model, one could conclude that time transformation does not appear to be a salient aspect of competitive athletes' flow experience. As noted by Jackson and Eklund (2002), time monitoring is a needed self-regulatory skill for optimal performance in certain types of sport. In sports requiring a vivid awareness of time passage, transformation of time could generate anxiety and disrupt the overall experience of flow. As of now, the status of transformation of time as an important dimension of the sport-related flow state remains equivocal.

\section{Cross-cultural invariance of the FSS-2}

Meaningful cross-cultural comparisons of flow state not only require good psychometric properties to be established in foreign languages, but it also necessitates the demonstration of measurement equivalence. In this study, measurement equivalence of the FSS-2 was tested within the confines of multiple-group HCFA. A main goal was to assess if the second-order loadings of the nine flow dimensions could be assumed invariant across French and English versions of the FSS-2. A prerequisite was to demonstrate that a majority of first-order factor loadings were invariant across languages to ensure that the nine flow dimensions had a similar psychological meaning across languages. Results of the multiple-group HCFA revealed that 25 out of the 27 first-order loadings constrained to equality were not significantly different across languages, thus indicating that the full metric invariance of seven flow dimensions could be assumed. Although items 18 and 25 were significantly different across languages, each was a significant indicator of its respective factor, with a substantial first-order loading in both languages. Given that only one item per factor was non-invariant, partial first-order metric invariance was tenable for autotelic experience and loss of selfconsciousness, thus ensuring the reliable comparison of the whole hierarchical model across languages.

Further analyses on the hierarchical model indicated that the second-order flow factor was construed somewhat differently across languages. Partial second-order invariance was assumed given that eight out of the nine second-order loadings were not significantly different across languages. Results indicated that the loading of autotelic experience on the second-order flow factor was significantly lower in the French FSS-2. From a conceptual standpoint, this result suggests that autotelic experience contributes more to overall flow state measured by the original FSS-2. From a methodological standpoint, however, it is important to report that the research design was somewhat different across samples. Specifically, all the French-speaking athletes completed the FSS-2 in reference to a sport competition whereas the English-speaking participants reported their flow state in reference to a mixture of sport and exercise activities. Sport competition is inherently more stressful than physical activities, which are pleasurable and revitalizing for a majority of exercisers. As noted by Jackson and Marsh (1996), enjoyment is seen as somewhat antithetical to the achievement-oriented nature of competitive sports. Autotelic experience might load more on the general flow factor in exercise settings than during sport competition, as suggested by the English-speaking sample which partially consisted of people involved in non-competitive exercise activities. An interesting avenue of inquiry would be to evaluate this hypothesis more directly in samples of exercisers and athletes. A within-subject design could also be insightful to compare flow state of individuals, such as studentathletes, across a wide range of activities such as competition, training, physical education classes, and perhaps even school-related tasks (e.g., exam, homework, writing assignments). Such investigations would lend relevance to the search of invariant and unique features of human flow experience across different life domains and populations. 
Along with testing the cross-cultural invariance of the FSS-2, this study examined the relationships between flow state and goal attainment during a sport competition. At a second-order level, a global dimension of flow correlated significantly with perceived goal attainment, and this relationship was invariant across expertise levels. Success in sport is not only a matter of outperforming opponents and achieving normative success. Interestingly, flow state was associated with the capacity of people of mastering the absolute requirements of the task as well as with the capacity of achieving one's maximum level of abilities. At a first-order level, all dimensions of flow-with the exception of time transformation and loss of self-consciousness-were significantly correlated with perceived goal attainment. However, changes in habitual sense of passing of time and losing self-consciousness were marginally associated to attainment of personal goals. This result mirrored those of the HCFA by showing that time transformation, and perhaps loss of self-consciousness, may be tangential components of the flow experience during sport competition. Overall, these results indicate that higher attainment of personal goals and flow state are highly interdependent during sport competition, thus providing evidence for the concurrent validity of the French version of the FSS-2. Whether goal attainment should be considered as an outcome, an antecedent, or a concomitant of flow state should be clarified using longitudinal designs as well as experimental studies allowing for manipulation of goal attainment feedback provided to the athletes.

\section{Limitations and conclusions}

This research relied solely on self-reported measures of flow state and goal attainment obtained retrospectively, thus showing that the factor structure of the FSS-2 can be applicable in settings where athletes are unavailable within hours after a competition. Despite these results, particular efforts should be made to measure flow and goal attainment closely after a competition to reduce retrospective biases caused by distortion of memory and posterior reinterpretation of the event. Research should also examine the convergence between flow scores obtained retrospectively and immediately after a sport competition to assess how long after an event people can still accurately report their flow state. Future investigations should also try to obtain coach-report and/or peer-report of goal attainment immediately after a competition to eliminate method variance biases that could artificially increase the correlation between flow and goal attainment. Alternatively, a group of athletes could be followed throughout a season to investigate the relationship between the frequency of flow and the seasonal attainment of personal goals rated by the athletes themselves and their coaches. Such a design would be insightful to address the seasonal fluctuation of flow state and to investigate whether the intensity and frequency of flow relate differently to goal attainment and changes in subjective well-being.

Research should also try to relate flow state within mounting literature examining the regulatory processes promoting goal attainment in competitive settings (Hoar, Kowalski, Gaudreau, \& Crocker, 2006). Prior research has revealed the influence of task-oriented coping strategies on goal attainment during sport competition (Gaudreau \& Blondin, 2004). A recent study also indicated that basic psychological skills related positively to flow state of athletes during competition (Jackson et al., 2001). Given the conceptual similarities of the psychological skills and coping constructs (Hoar et al., 2006), it would be interesting to investigate the role of preparatory coping strategies in the promotion of flow state and goal attainment. Preparatory coping strategies are used during the days leading to an important competitive encounter. Higher reliance on task-oriented coping strategies such as relaxation, effort expenditure, logical analyses, mental imagery, and thought control might pave the way to optimal functioning during competition. Momentary utilization of distraction-oriented strategies could also favour optimal functioning through the preservation of the limited self-regulatory energy needed to compete in ego-evolving situations (Gaudreau \& Blondin, 2004). A better understanding of the self-regulatory strategies associated with flow state and successful goal pursuit is a promising research avenue for the development of empirically driven sport psychology interventions.

This study examined the factor structure of the FSS-2 across two languages originating from occidental and mostly individualistic cultures. One could contend that the underlying dimensions of flow are somewhat rooted within an individualistic culture of self-oriented competence and achievement. Little attention has been devoted to flow in cultures and group settings where competence and well-being are derived mostly from relatedness with the social group and from the attainment of collective goals. Whether the underlying dimensions of flow and the factors that facilitate 
it are different in group-oriented collectivist cultures is an issue that warrants further investigations. Such an issue is also important for team sport in which collective flow state might be experienced over and above flow state at an individual-level. Future studies should inquire about within-group processes such as leadership and cohesion that could produce social contagion of flow in small team setting. As of now, this study provides a much-needed reliable International French translation of the FSS-2 that will hopefully stimulate research activities on the flow construct across French-speaking communities.

\section{Acknowledgements}

Jean Fournier and Patrick Gaudreau played equal roles in the preparation of this article. This research was supported by a regular research grant from Social Sciences and Humanities Research Council of Canada awarded to Patrick Gaudreau. We thank Robert Eklund for sharing published data for the cross-cultural analyses as well as Patrick Migneault for his involvement in the project. Parts of this paper were presented at the 2004 European Conference of Positive Psychology.

\section{References}

Aguinis (2004) H. Aguinis, Regression analyses for categorical moderators, Guilford Press, New York (2004).

Beedie, Terry, \& Lane (2000) C.J. Beedie, P.C. Terry and A.M. Lane, The profile of mood state and athletes performance: Two meta-analysis, Journal of Applied Sport Psychology 12 (2000), pp. 49-68.

Bentler (1995) P.M. Bentler, EQS structural equations program manual, Multivariate Software, Encino, CA (1995).

Burton (1998) D. Burton, Measuring competitive state anxiety. In: J.L. Duda, Editor, Advances in sport and exercise psychology measurement, Fitness Information Technology, Morgantown, WV (1998), pp. $129-148$.

Byrne, Shavelson, \& Muthén (1989) B.M. Byrne, R.J. Shavelson and B. Muthén, Testing for the equivalence of factor covariance and mean structures: The issue of partial measurement invariance, Psychological Bulletin 88 (1989), pp. 456-466.

Carpenter, Scanlan, Simons, \& Lobel (1993) P.J. Carpenter, T.K. Scanlan, J.P. Simons and M. Lobel, A test of the sport commitment model using structural equation modeling, Journal of Sport and Exercise Psychology 15 (1993), pp. 119-133.

Cheung \& Rensvold (2002) G.W. Cheung and R.B. Rensvold, Evaluating goodness-of-fit indexes for testing measurement invariance, Structural Equation Modeling 9 (2002), pp. 233-255.

Cohen, Cohen, West, \& Aiken (2003) J. Cohen, P. Cohen, S.G. West and L.S. Aiken, Applied multiple regression/correlation analysis for the behavioral sciences (3rd ed.), Lawrence Erlbaum, Mahwah, NJ (2003).

Cohn (1991) P. Cohn, An exploratory study on peak performance in golf, The Sport Psychologist 5 (1991), pp. 1-14.

Crocker \& Graham (1995) P.R. Crocker and T.R. Graham, Emotion in sport and physical activity: The importance of individual goals, International Journal of Sport Psychology 26 (1995), pp. 117-137.

Csikszentmihalyi (1990) M. Csikszentmihalyi, Flow: The psychology of optimal experience, Harper \& Row, New York (1990). 
Csikszentmihalyi \& Csikszentmihalyi (1988) M. Csikszentmihalyi and I. Csikszentmihalyi, Optimal experience: Psychological study of flow in consciousness, Harper \& Row, New York (1988).

Elliot \& Dweck (2005) A.J. Elliot and C.S. Dweck, Competence and motivation: Competence as the core of achievement motivation. In: A.J. Elliot and C.S. Dweck, Editors, Handbook of competence and motivation, Guilford Press, New York (2005), pp. 3-12.

Forest (2001) Forest, J. (2001). Étude de l'état psychologique de flow chez les athlètes élites en planche à neige [A study of flow state in snowboarding elite athletes]. Unpublished Masters' Thesis, Université de Montréal, Montreal, PQ.

Gaudreau, Amiot, Blondin, \& Blanchard (2002) Gaudreau, P., Amiot, C. E., Blondin, J.-P., \& Blanchard, C. M. (2002, November). A hierarchical model of goal attainment in sport competition. Paper presented at the annual meeting of the Canadian Society for Psychomotor Learning and Sport Psychology, Vancouver, BC.

Gaudreau \& Blondin (2004) P. Gaudreau and J.-P. Blondin, The differential associations of dispositional optimism and pessimism with coping, goal attainment, and emotional adjustment during a sport competition, International Journal of Stress Management 11 (2004), pp. 245-269.

Gould, Jackson, \& Finch (1993) D. Gould, S.A. Jackson and L. Finch, Sources of stress in national champion figure skaters, Journal of Sport and Exercise Psychology 15 (1993), pp. 134-159.

Green, Thompson, \& Babyak (1998) S.B. Green, M.S. Thompson and M.A. Babyak, A Monte Carlo investigation of methods for controlling type I errors with specification searches structural equation modeling, Multivariate Behavioral Research 33 (1998), pp. 365-383.

Hanin (2000) Y.L. Hanin, Emotions in sport, Human Kinetics, Champaign, IL (2000).

Hoar, Kowalski, Gaudreau, \& Crocker (2006) S.D. Hoar, K.C. Kowalski, P. Gaudreau and P.R. Crocker, A review of coping in sport. In: S. Hanton and S.D. Mellalieu, Editors, Literature reviews in sport psychology, Nova Science, New York (2006), pp. 47-90.

Isberg (2000) L. Isberg, Anger, aggressive behavior, and athletic performance. In: Y.L. Hanin, Editor, Emotions in sport, Human Kinetics, Champaign, IL (2000), pp. 113-134.

Jackson (1992) S.A. Jackson, Athletes in flow: A qualitative investigation of flow states in elite figure skaters, Journal of Applied Sport Psychology 4 (1992), pp. 161-180.

Jackson (1995) S.A. Jackson, Factors influencing the occurence of flow states in elite athletes, Journal of Applied Sport Psychology 7 (1995), pp. 138-166.

Jackson (2000) S.A. Jackson, Joy, fun, and flow state in sport. In: Y.L. Hanin, Editor, Emotions in sport, Human Kinetics, Champaign, IL (2000), pp. 135-156.

Jackson \& Eklund (2002) S.A. Jackson and R.C. Eklund, Assessing flow in physical activity: The Flow State Scale-2 and Dispositional Flow State Scale-2, Journal of Sport and Exercise Psychology 24 (2002), pp. 115-133.

Jackson, Kimiecik, Ford, \& Marsh (1998) S.A. Jackson, J.C. Kimiecik, S.K. Ford and H.W. Marsh, Psychological correlates of flow, Journal of Sport and Exercise Psychology 20 (1998), pp. 358-378.

Jackson \& Marsh (1996) S.A. Jackson and H.W. Marsh, Development and validation of a scale to measure optimal experience: The Flow State Scale, Journal of Sport and Exercise Psychology 18 (1996), pp. 17-35. 
Jackson \& Roberts (1992) S.A. Jackson and G.C. Roberts, Positive performance states of athletes: Toward a conceptual understanding of peak performance, The Sport Psychologist 6 (1992), pp. 156171.

Jackson, Thomas, Marsh, \& Smethurst (2001) S.A. Jackson, P.R. Thomas, H.W. Marsh and C.J. Smethurst, Relationships between flow, self-concept, psychological skills, and performance, Journal of Applied Sport Psychology 13 (2001), pp. 129-153.

Karageorghis, Vlachopoulos, \& Terry (2000) C.I. Karageorghis, S.P. Vlachopoulos and P.C. Terry, Latent variable modelling of the relationship between flow and exercise-induced feeling: An intuitive approach perspective, European Physical Education Review 6 (2000), pp. 230-248.

Kleine (1990) D. Kleine, Anxiety and sport performance: A meta-analysis, Anxiety Research 2 (1990), pp. 113-131.

Kowal \& Fortier (2000) J. Kowal and M.S. Fortier, Testing relationships from the hierarchical model of intrinsic and extrinsic motivation using flow as a motivational consequence, Research Quarterly for Exercise and Sport 71 (2000), pp. 171-181.

MacCallum, Browne, \& Sugawara (1996) R.C. MacCallum, M.W. Browne and H.M. Sugawara, Power analysis and determination of sample size for covariance structure model, Psychological Methods 1 (1996), pp. 130-149.

Madden et al. (1995) C.C. Madden, R.J. Kirkby, D. McDonald, J.J. Summers, D.F. Brown and N.J. King, Stressful situations in competitive basketball, Australian Psychologist 30 (1995), pp. 119-124.

Marsh \& Jackson (1999) H.W. Marsh and S.A. Jackson, Flow experience in sport: Construct validation of multidimensional, hierarchical state and trait responses, Structural Equation Modeling 6 (1999), pp. 343-371.

Riemer \& Chelladurai (1998) H.A. Riemer and P. Chelladurai, Development of the Athletic Satisfaction Questionnaire, Journal of Sport and Exercise Psychology 20 (1998), pp. 127-156.

Steenkamp \& Baumgartner (1998) J.E. Steenkamp and H. Baumgartner, Assessing measurement invariance in cross-national consumer research, Journal of Consumer Research 25 (1998), pp. 78-90.

Tomarken \& Waller (2003) A.J. Tomarken and N.G. Waller, Potential problems with "well-fitting" models, Journal of Abnormal Psychology 112 (2003), pp. 578-598.

Vandenberg \& Lance (2000) R.J. Vandenberg and C.E. Lance, Review and synthesis of the measurement invariance literature: Suggestions, practices, and recommendations for organizational research, Organizational Research Methods 3 (2000), pp. 4-69.

Vlachopoulos, Karageorghis, \& Terry (2000) S.P. Vlachopoulos, C.I. Karageorghis and P. Terry, Hierarchical confirmatory factor analysis of the Flow State Scale in exercise, Journal of Sport Sciences 18 (2000), pp. 815-823.

West, Finch, \& Curran (1995) S.G. West, J.F. Finch and P.J. Curran, Structural equation models with nonnormal variables. In: R.H. Hoyle, Editor, Structural equation modeling: Concepts, issues, and applications, Sage Publications, Thousand Oaks (1995), pp. 56-75. 


\section{Notes}

${ }^{1} X^{2}(558)=1453.17, p<0.001 ; \mathrm{CFI}=0.813, \mathrm{NNFI}=0.789, \mathrm{RMSEA}=0.077, \mathrm{RMSEA} 90 \% \mathrm{Cl}=0.072-0.082$.

${ }^{2} \mathrm{X}^{2}(398)=910.83, \mathrm{p}<0.001 ; \mathrm{CFI}=0.879, \mathrm{NNFI}=0.858, \mathrm{RMSEA}=0.069, \mathrm{RMSEA} 90 \% \mathrm{Cl}=0.063-0.075$.

${ }^{3}$ Athletes under 16 years of age represented only $16 \%$ of this sample. Preliminary analyses indicated that age was mostly unrelated to the 36 items of the French FSS-2 (average $r=|0.06|$, range -0.23 to $0.13)$, with only three items correlating significantly with age $(p<0.01)$. Furthermore, age was unrelated to the Mahalanobis distance, a measure of multivariate outlying cases $(r=-0.06, p>0.10)$. All athletes regardless of their age were included in the analyses considering that items of the French FSS-2 were easy to understand and because younger athletes were part of the population that we intended to sample.

${ }^{4}$ The robust statistics were not available for multiple-sample HCFA, which were uncorrected for nonnormality.

${ }^{5}$ Additional multiple-group analyses were performed on the first-order model and yielded similar results for the first-order metric invariance. Constraining the 36 covariances to equality produced a significant decrement in model fit, $\Delta \mathrm{x}^{2}=63.39, \Delta \mathrm{df}=36, \mathrm{p}<0.01, \Delta \mathrm{CFI}=-0.002$. However, only two covariances could not be assumed invariant across languages: concentration and loss of selfconsciousness, $\mathrm{LMX}{ }^{2}=6.59, \mathrm{p}=0.01, \varphi_{\text {French }}=0.39, \varphi_{\text {English }}=0.24$; concentration and action-awareness, $\mathrm{LMx}^{2}=7.86, p<0.01, \varphi_{\text {French }}=0.49, \varphi_{\text {English }}=0.36$. These results provided evidence for the partial invariance of covariances across languages.

${ }^{6}$ The interaction between flow and expertise level was not significant $(p>0.05)$ in predicting any of the specific subscales of goal attainment (i.e., mastery, self-referenced, and normative goal attainment). Results of these analyses are available upon request. 


\section{Tables}

\section{Table 1.}

Alpha coefficient of internal consistency of the original and French Flow State Scale-2

\begin{tabular}{|c|c|c|}
\hline & Jackson and Eklund (2002) & French FSS-2 \\
\hline & $\alpha$ & $\alpha$ \\
\hline Challenge-skill balance & 0.83 & 0.81 \\
\hline Action awareness & 0.90 & 0.79 \\
\hline Clear goals & 0.87 & 0.80 \\
\hline Unambiguous feedback & 0.88 & 0.82 \\
\hline Concentration & 0.88 & 0.88 \\
\hline Sense of control & 0.88 & 0.87 \\
\hline Loss of self-consciousness & 0.92 & 0.92 \\
\hline Time transformation & 0.80 & 0.85 \\
\hline Autotelic experience & 0.91 & 0.91 \\
\hline
\end{tabular}


Table 2.

Fit indices for the first-order and hierarchical models of the French Flow State Scale-2 and crosscultural invariance analyses

\begin{tabular}{|c|c|c|c|c|c|c|c|c|c|c|c|}
\hline Models & $x^{2}$ & $\mathrm{SBx}{ }^{2}$ & df & CFI & $\mathrm{RCFI}$ & NNFI & RMSEA & $\begin{array}{l}\text { RMSEA } \\
90 \% \mathrm{Cl}\end{array}$ & $\Delta x^{2}$ & $\Delta \mathrm{df}$ & $\triangle \mathrm{CFI}$ \\
\hline \multicolumn{12}{|c|}{ French Flow State Scale-2 } \\
\hline First-order model & 1088.42 & 979.23 & 558 & 0.939 & 0.941 & 0.931 & 0.050 & $\begin{array}{l}0.045 \\
0.054\end{array}$ to & - & - & - \\
\hline $\begin{array}{l}\text { Hierarchical } \\
\text { model }\end{array}$ & 1186.72 & 1064.14 & 585 & 0.931 & 0.933 & 0.926 & 0.052 & $\begin{array}{l}0.047 \\
0.056\end{array}$ & - & - & - \\
\hline \multicolumn{12}{|c|}{ Cross-cultural invariance analyses } \\
\hline 1. Configural & 2491.79 & NA & 1170 & 0.930 & NA & 0.924 & 0.037 & $\begin{array}{l}0.035 \\
0.039\end{array}$ & & & \\
\hline $\begin{array}{l}\text { 2a. Full 1st-order } \\
\text { metric }\end{array}$ & 2550.67 & NA & 1197 & 0.928 & NA & 0.924 & 0.037 & $\begin{array}{l}0.035 \text { to } \\
0.039\end{array}$ & & & \\
\hline $2 a$ vs. 1 & & & & & & & & & $58.88^{* *}$ & 27 & -0.002 \\
\hline $\begin{array}{l}\text { 2b. Partial 1st- } \\
\text { order metric }\end{array}$ & 2522.11 & NA & 1195 & 0.929 & NA & 0.926 & 0.037 & $\begin{array}{l}0.035 \text { to } \\
0.039\end{array}$ & & & \\
\hline $2 b$ vs. 1 & & & & & & & & & 30.22 & 25 & -0.001 \\
\hline $\begin{array}{l}\text { 3a. Full 2nd-order } \\
\text { metric }\end{array}$ & 2540.70 & NA & 1204 & 0.929 & NA & 0.926 & 0.037 & $\begin{array}{l}0.035 \\
0.039\end{array}$ to & & & \\
\hline 3 vs. $2 b$ & & & & & & & & & $18.58^{*}$ & 9 & -0.000 \\
\hline $\begin{array}{l}\text { 3b. Partial 2nd- } \\
\text { order metric }\end{array}$ & 2530.86 & NA & 1203 & 0.929 & NA & 0.926 & 0.037 & $\begin{array}{l}0.035 \text { to } \\
0.039\end{array}$ & & & \\
\hline $3 b$ vs. $2 b$ & & & & & & & & & 8.75 & 8 & -0.000 \\
\hline 4a. Full error & 3094.38 & NA & 1248 & 0.902 & NA & 0.901 & 0.043 & $\begin{array}{l}0.041 \\
0.045\end{array}$ to & & & \\
\hline $4 a$ vs. $3 b$ & & & & & & & & & $563.52^{\star *}$ & 45 & -0.027 \\
\hline 4b. Partial error & 2571.39 & NA & 1229 & 0.928 & NA & 0.927 & 0.037 & $\begin{array}{l}0.035 \text { to } \\
0.039\end{array}$ & & & \\
\hline $4 b$ vs. $3 b$ & & & & & & & & & $40.53^{*}$ & 26 & -0.001 \\
\hline
\end{tabular}

Note. All $X^{2}$ and $\mathrm{SBX}^{2}$ were significant at $\mathrm{p}<0.001 . \mathrm{NA}=$ not available in multiple-group analyses.

${ }^{*} p<0.05$.

${ }^{* *} p<.01$. 
Table 3.

Standardized factor loadings and uniquenesses of items from the French FSS-2

\begin{tabular}{|c|c|c|c|c|c|c|}
\hline & \multicolumn{3}{|c|}{ First-order parameters } & \multicolumn{3}{|c|}{ Second-order parameters } \\
\hline & SL & $E$ & $\mathrm{R}^{2}$ & SL & $\mathrm{D}$ & $\mathrm{R}^{2}$ \\
\hline Challenge-skill balance & & & & 0.785 & 0.619 & 0.617 \\
\hline Item $1^{a}$ & 0.420 & 0.908 & 0.176 & & & \\
\hline Item 10 & 0.788 & 0.615 & 0.622 & & & \\
\hline Item 19 & 0.808 & 0.589 & 0.653 & & & \\
\hline Item 28 & 0.887 & 0.462 & 0.786 & & & \\
\hline Action awareness & & & & 0.645 & 0.764 & 0.417 \\
\hline Item $2^{\mathrm{a}}$ & 0.704 & 0.710 & 0.496 & & & \\
\hline Item 11 & 0.795 & 0.606 & 0.633 & & & \\
\hline Item 20 & 0.805 & 0.593 & 0.648 & & & \\
\hline Item 29 & 0.817 & 0.577 & 0.668 & & & \\
\hline Clear goals & & & & 0.726 & 0.688 & 0.527 \\
\hline Item $3^{\mathrm{a}}$ & 0.705 & 0.709 & 0.497 & & & \\
\hline Item 12 & 0.752 & 0.659 & 0.566 & & & \\
\hline Item 21 & 0.627 & 0.779 & 0.393 & & & \\
\hline Item 30 & 0.756 & 0.654 & 0.572 & & & \\
\hline Unambiguous feedback & & & & 0.817 & 0.576 & 0.668 \\
\hline Item $4^{\mathrm{a}}$ & 0.645 & 0.764 & 0.416 & & & \\
\hline Item 13 & 0.557 & 0.830 & 0.311 & & & \\
\hline Item 22 & 0.771 & 0.637 & 0.594 & & & \\
\hline Item 31 & 0.598 & 0.802 & 0.357 & & & \\
\hline Concentration & & & & 0.744 & 0.668 & 0.553 \\
\hline Item $5^{\mathrm{a}}$ & 0.791 & 0.611 & 0.626 & & & \\
\hline Item 14 & 0.845 & 0.535 & 0.713 & & & \\
\hline Item 23 & 0.893 & 0.450 & 0.798 & & & \\
\hline Item 32 & 0.909 & 0.417 & 0.826 & & & \\
\hline
\end{tabular}




\begin{tabular}{|c|c|c|c|c|c|c|}
\hline & \multicolumn{3}{|c|}{ First-order parameters } & \multicolumn{3}{|c|}{ Second-order parameters } \\
\hline & SL & $E$ & $\mathrm{R}^{2}$ & SL & $\mathrm{D}$ & $\mathrm{R}^{2}$ \\
\hline Sense of control & & & & 0.910 & 0.414 & 0.829 \\
\hline Item $6^{\underline{a}}$ & 0.761 & 0.648 & 0.580 & & & \\
\hline Item 15 & 0.761 & 0.648 & 0.580 & & & \\
\hline Item 24 & 0.826 & 0.564 & 0.682 & & & \\
\hline Item 33 & 0.805 & 0.593 & 0.649 & & & \\
\hline Loss of self-consciousness & & & & 0.455 & 0.891 & 0.207 \\
\hline Item $7^{\mathrm{a}}$ & 0.914 & 0.405 & 0.836 & & & \\
\hline Item 16 & 0.938 & 0.346 & 0.880 & & & \\
\hline Item 25 & 0.685 & 0.728 & 0.470 & & & \\
\hline Item 34 & 0.900 & 0.436 & 0.810 & & & \\
\hline Time transformation & & & & 0.126 & 0.992 & 0.016 \\
\hline Item $8^{\underline{a}}$ & 0.843 & 0.538 & 0.711 & & & \\
\hline Item 17 & 0.873 & 0.487 & 0.762 & & & \\
\hline Item 26 & 0.530 & 0.848 & 0.280 & & & \\
\hline Item 35 & 0.847 & 0.531 & 0.718 & & & \\
\hline Autotelic experience & & & & 0.476 & 0.879 & 0.227 \\
\hline Item $9^{\mathrm{a}}$ & 0.864 & 0.504 & 0.746 & & & \\
\hline Item 18 & 0.866 & 0.501 & 0.749 & & & \\
\hline Item 27 & 0.912 & 0.410 & 0.832 & & & \\
\hline Item 36 & 0.727 & 0.687 & 0.528 & & & \\
\hline
\end{tabular}

Note. SL=standardized loading. $E=$ standardized uniqueness (the variance unaccounted by the factor is obtained by squaring the reported value). $D=$ standardized disturbance (the variance unaccounted by the factor is obtained by squaring the reported value). All parameters were significant at $p<0.05$. ${ }^{\text {a }}$ Parameters fixed at 1.0 to set the metric of the latent construct. 


\section{Table 4.}

Standardized covariances between subscales of the French FSS-2

\begin{tabular}{|l|l|l|l|l|l|l|l|l|l|}
\hline Flow dimensions & 1 & 2 & 3 & 4 & 5 & 6 & 7 & 8 & 9 \\
\hline 1. Challenge-skill balance & - & & & & & & & & \\
\hline 2. Action awareness & 0.50 & - & & & & & & & \\
\hline 3. Clear goals & 0.54 & 0.40 & - & & & & & & \\
\hline 4. Unambiguous feedback & 0.65 & 0.49 & 0.68 & - & & & & & \\
\hline 5. Concentration & 0.53 & 0.49 & 0.58 & 0.59 & - & & & & \\
\hline 6. Sense of control & 0.74 & 0.61 & 0.60 & 0.76 & 0.67 & - & & & \\
\hline 7. Loss of self-consciousness & 0.30 & 0.36 & 0.41 & 0.34 & 0.39 & 0.38 & - & & \\
\hline 8. Time transformation & $0.10^{\mathrm{a}}$ & 0.15 & $0.06^{\mathrm{a}}$ & $0.05^{\mathrm{a}}$ & $0.11^{\mathrm{a}}$ & $0.08^{\mathrm{a}}$ & $0.11^{\mathrm{a}}$ & - & \\
\hline 9. Autotelic experience & 0.46 & 0.26 & 0.33 & 0.22 & 0.43 & 0.43 & 0.24 & 0.24 & - \\
\hline
\end{tabular}

${ }^{a} p>0.05$ (the association was not significant). All other correlations were significant. 
Table 5.

Zero-order correlations between flow dimensions and goal attainment indices

\begin{tabular}{|l|l|l|l|l|}
\hline Flow dimensions & $\begin{array}{l}\text { Global goal } \\
\text { attainment }\end{array}$ & $\begin{array}{l}\text { Mastery goal } \\
\text { attainment }\end{array}$ & $\begin{array}{l}\text { Self-referenced goal } \\
\text { attainment }\end{array}$ & $\begin{array}{l}\text { Normative goal } \\
\text { attainment }\end{array}$ \\
\hline $\begin{array}{l}\text { Challenge-skill } \\
\text { balance }\end{array}$ & 0.56 & 0.59 & 0.40 & 0.53 \\
\hline Action awareness & 0.41 & 0.46 & 0.30 & 0.36 \\
\hline Clear goals & 0.40 & 0.47 & 0.24 & 0.40 \\
\hline $\begin{array}{l}\text { Unambiguous } \\
\text { feedback }\end{array}$ & 0.35 & 0.44 & 0.17 & 0.36 \\
\hline Concentration & 0.55 & 0.68 & 0.38 & 0.46 \\
\hline Sense of control & 0.56 & 0.61 & 0.41 & 0.51 \\
\hline $\begin{array}{l}\text { Loss of } \\
\text { consciousness }\end{array}$ & 0.21 & 0.28 & $0.12^{\mathrm{a}}$ & 0.20 \\
\hline Time transformation & $0.10^{\mathrm{a}}$ & $0.03^{\mathrm{a}}$ & $0.12^{\mathrm{a}}$ & $0.12^{\mathrm{a}}$ \\
\hline Autotelic experience & 0.58 & 0.53 & 0.56 & 0.46 \\
\hline Global flow & 0.64 & 0.69 & 0.47 & 0.58 \\
\hline
\end{tabular}

Note. $\mathrm{N}=387$.

${ }^{\mathrm{a}} \mathrm{p}>0.01$ (the association was not significant). All other correlations were significant at $\mathrm{p}<0.001$. 